Full Length Article

\title{
Layer-by-layer composite film of nickel phthalocyanine and montmorillonite clay for synergistic effect on electrochemical detection of dopamine
}

\author{
Nathalia C. de Lucena ${ }^{\mathrm{a}}$, Celina M. Miyazaki ${ }^{\mathrm{a}, *}$, Flávio M. Shimizu ${ }^{\mathrm{b}}$, \\ Carlos J.L. Constantino ${ }^{c}$, Marystela Ferreira ${ }^{\mathrm{a}, *}$ \\ a Universidade Federal de São Carlos, Sorocaba, SP, Brazil \\ b Universidade de São Paulo, São Carlos, SP, Brazil

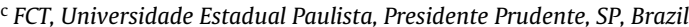

\section{A R T I C L E I N F O}

\section{Article history:}

Received 23 August 2017

Received in revised form

17 November 2017

Accepted 14 December 2017

Available online 19 December 2017

\section{Keywords:}

Dopamine

Layer-by-layer

Nickel phthalocyanine

Montmorillonite clay

Electrochemical sensor

\begin{abstract}
A B S T R A C T
Dopamine (DA) abnormal levels are related to diseases which makes important the development of fast, reliable, low-cost and sensitive devices for diagnosis and pharmaceutical controls. Nanostructured film composite of sodium montmorillonite clay ( $\mathrm{Na}^{+} \mathrm{MMT}$ ) and nickel phthalocyanine (NiTsPc) was selfassembled by layer-by-layer ( $\mathrm{LbL}$ ) technique and applied as electrochemical sensor for DA in the presence of common natural interferents as ascorbic acid (AA) and uric acid (UA). Three different LbL architecture films were investigated: LbL films of clay (PEI/Na ${ }^{+} \mathrm{MMT}$ ) and phthalocyanine (PEI/NiTsPc) in a bilayer structure with a conventional polyelectrolyte (PEI) and a composite film formed by both materials to verify the synergistic effect in the LbL film in a quadri-layer assembly (PEI/Na ${ }^{+} \mathrm{MMT} / \mathrm{PEI} / \mathrm{NiTsPc}$ ). Structural characterization indicated molecular level interactions between the layers forming the LbL films. The ITO/(PEI/Na $\left.{ }^{+} \mathrm{MMT} / \mathrm{PEI} / \mathrm{NiTsPc}\right)_{10}$ electrode exhibited a LOD of $1.0 \mu \mathrm{mol} \mathrm{L}^{-1}$ and linear range 5-150 $\mu \mathrm{mol} \mathrm{L}^{-1}$.
\end{abstract}

(c) 2017 Elsevier B.V. All rights reserved.

\section{Introduction}

Dopamine (DA) is a neurotransmitter with a fundamental function in the central nervous system. It deliveries information to the cells acting specially in the control of movement, pleasure sensation, besides being metabolic precursor for noradrenaline and adrenaline [1]. Normal dopamine level in blood is very low and it varies between $0.01-1.0 \mu \mathrm{mol} \mathrm{L}^{-1}$ [2] and its abnormal level can result in diseases [3-5], as Huntington's disease, Alzheimer's and Parkinson's diseases, where the dopamine activity is lower than healthy individuals [6]. On the opposite, Schizophrenia is connected to increased dopaminergic activity [6]. Due to the relevance of dopamine quantification for healthy monitoring and pharmaceutical control, the development of simple, fast and inexpensive methods for DA quantification has been focus of attention for many researchers in the last decades. Some reviews encompassing the sensor development for DA are published in the last years $[1,7,8]$.

\footnotetext{
* Corresponding authors.

E-mail addresses: celinamiyazaki@ufscar.br (C.M. Miyazaki), marystela@ufscar.br (M. Ferreira).
}

Among the DA quantification techniques the electrochemical method has presented advantages as fast response and low cost [8]. Advances in electrode modifications allow high sensitivity and selectivity $[1,8]$. However, DA coexists in the extracellular fluids of the central nervous system with two electrochemical interferents, ascorbic acid (AA) and uric acid (UA), both present in higher concentration and exhibiting oxidation potential very close to DA [9]. In this way, the development of modified electrodes with high selectivity to DA has been focus of extensively work, including applications of a plenty of materials, as metal nanoparticles [9], conducting polymers [10], carbon nanotubes [11,12], graphene [4,9,10,13-15], specific enzymes [16], among others. For instance, Uzun et al. developed a sensor composed by $N, N$ '-bis(indole3-carboxaldimine)-1,2-diaminocyclohexane onto glassy carbon electrode, which is capable to separate the oxidation peaks of DA, AA and UA by the differential pulse voltammetry with limit of detection of DA equal to $0.18 \mu \mathrm{mol} \mathrm{L}^{-1}$ [17]. Recently, Daniel Arulraj et al. achieved very low limit of detection ( $20 \mathrm{nM})$ using modified GCE electrodes via electrochemical reduction of graphene oxide followed by electropolymerization of polypyrrole forming a composite film for selective determination of DA in presence of DA and UA [10]. 
A

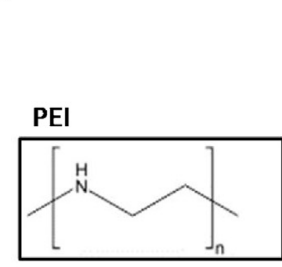

NiTsPc

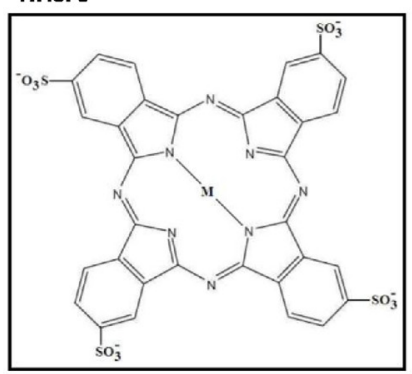

Na'MMT

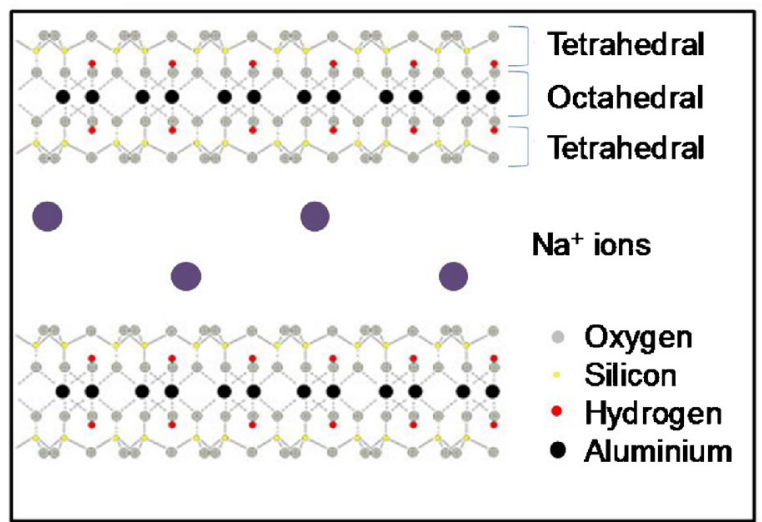

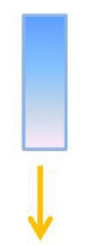

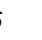


bath with isopropyl alcohol for $10 \mathrm{~min}$. Three different LbL architected films were investigated: LbL films of clay (PEI/Na ${ }^{+} \mathrm{MMT}$ ) and phthalocyanine (PEI/NiTsPc) in a bilayer structure with a conventional polyelectrolyte (PEI) and a composite film formed by both materials to verify the synergistic effect in the LbL film in a quadri-layer assembly (PEI/Na+ ${ }^{+} \mathrm{MMT} / \mathrm{PEI} / \mathrm{NiTsPc}$ ). Fig. $1 \mathrm{~A}$ shows the chemical structure of PEI, NiTsPc and $\mathrm{Na}^{+}$MMT. Fig. 1B depicts a schematic diagram of fabrication of quadri-layer film (PEI/Na ${ }^{+} \mathrm{MMT} / \mathrm{PEI} / \mathrm{NiTsPc}$ ): firstly, the substrate was immersed in the PEI cationic solution for $3 \mathrm{~min}$, followed by immersion in the $\mathrm{Na}^{+} \mathrm{MMT}$ anionic suspension for $10 \mathrm{~min}$, one more immersion in the PEI solution for $3 \mathrm{~min}$, and finally, immersion in the NiTsPc anionic suspension for $5 \mathrm{~min}$. Between each deposition step, a washing was performed immerging the substrate into a buffer solution for $30 \mathrm{~s}$ to remove the weakly adsorbed material and also to avoid cross contamination. The deposition step can be repeated $n$ times then forming (PEI/Na $\left.{ }^{+} \mathrm{MMT} / \mathrm{PEI} / \mathrm{NiTsPc}\right)_{n}$ multilayer films.

\subsection{Layer-by-layer films characterization}

The deposition of (PEI/Na $\left.{ }^{+} \mathrm{MMT} / \mathrm{PEI} / \mathrm{NiTsPc}\right)_{n}$ film on quartz substrates was monitored using an UV-vis spectrometer Thermo Scientific Genesys 10 by absorbance measurements after each step. For the structural characterization, films were deposited on $\mathrm{Si}$ substrates and analysed by a Thermo Nicolet Nexus 470 FTIR spectrophotometer and a micro-Raman Renishaw, model in-Via, with active $632.8 \mathrm{~nm}$ laser. Mica substrates were previously peeled off and used for film deposition for morphology analysis using an atomic force microscope from Bruker (Bruker Corp., EUA) in tapping mode, and scanning rate of $0.8 \mathrm{~Hz}$. The images were analysed by Gwyddion software.

\subsection{Electrochemical measurements}

The LbL films were deposited on ITO-coated glass slides (Delta Technologies, USA) previously cleaned following the steps: immersion in chloroform and drying; immersion in isopropyl alcohol in an ultrasonic bath for $30 \mathrm{~min}$. Finally, they were washed extensively with ultrapure water and dried before film deposition. The electrochemical measurements were performed in a potenciostat/galvanostat from AutoLab model PGSTAT30, using a 3-electrode cell with $10 \mathrm{~mL}$ of supporting electrolyte of $\mathrm{pH} 7.0$ phosphate buffer. Platinum foil $\left(1.0 \mathrm{~cm}^{2}\right)$ and saturated calomel electrode (SCE) were used as counter-electrode and reference electrode, respectively, while the working electrode was the ITO covered with the different LbL films. Firstly, the measurements were performed using $0.1 \mathrm{~mol} \mathrm{~L}^{-1} \mathrm{pH}$ 7.0 PBS as electrolyte solution. In order to evaluate the sensor applicability in real samples it was also tested in human urine without any previous treatment or dilution, spiked with $3.0 \mu \mathrm{mol} \mathrm{L}^{-1}$ of dopamine. Differential pulse voltammetry (DPV) measurements were performed with step potential of $6.0 \mathrm{mV}$, pulse amplitude of $50 \mathrm{mV}$ and modulation time of $8.0 \mathrm{~ms}$.

\section{Results and discussions}

\subsection{Layer-by-layer films characterization}

Fig. 2 shows the absorption spectra obtained after each deposition step of the LbL films of (A) (PEI/Na $\left.{ }^{+} \mathrm{MMT}\right)_{10}$, (B) (PEI/NiTsPc) $)_{10}$, and $(\mathrm{C})\left(\mathrm{PEI} / \mathrm{Na}^{+} \mathrm{MMT} / \mathrm{PEI} / \mathrm{NiTsPc}\right)_{10}$. The $\left(\mathrm{PEI} / \mathrm{Na}^{+} \mathrm{MMT}\right)_{10}$ film (see Fig. 2A) presented a characteristic band at $244 \mathrm{~nm}$ due to the excitations of free electrons from $\mathrm{Fe}-\mathrm{OH}$ in the crystalline structure of clays [35]. The inset shows the poor linear growth $\left(R^{2}=0.8896\right)$ of this assembly. The main bands of NiTsPc were observed in both (B) $(\mathrm{PEI} / \mathrm{NiTsPc})_{10}$ and $(\mathrm{C})\left(\mathrm{PEI} / \mathrm{Na}^{+} \mathrm{MMT} / \mathrm{PEI} / \mathrm{NiTsPc}\right)_{10}$. The $\mathrm{S}$ band at
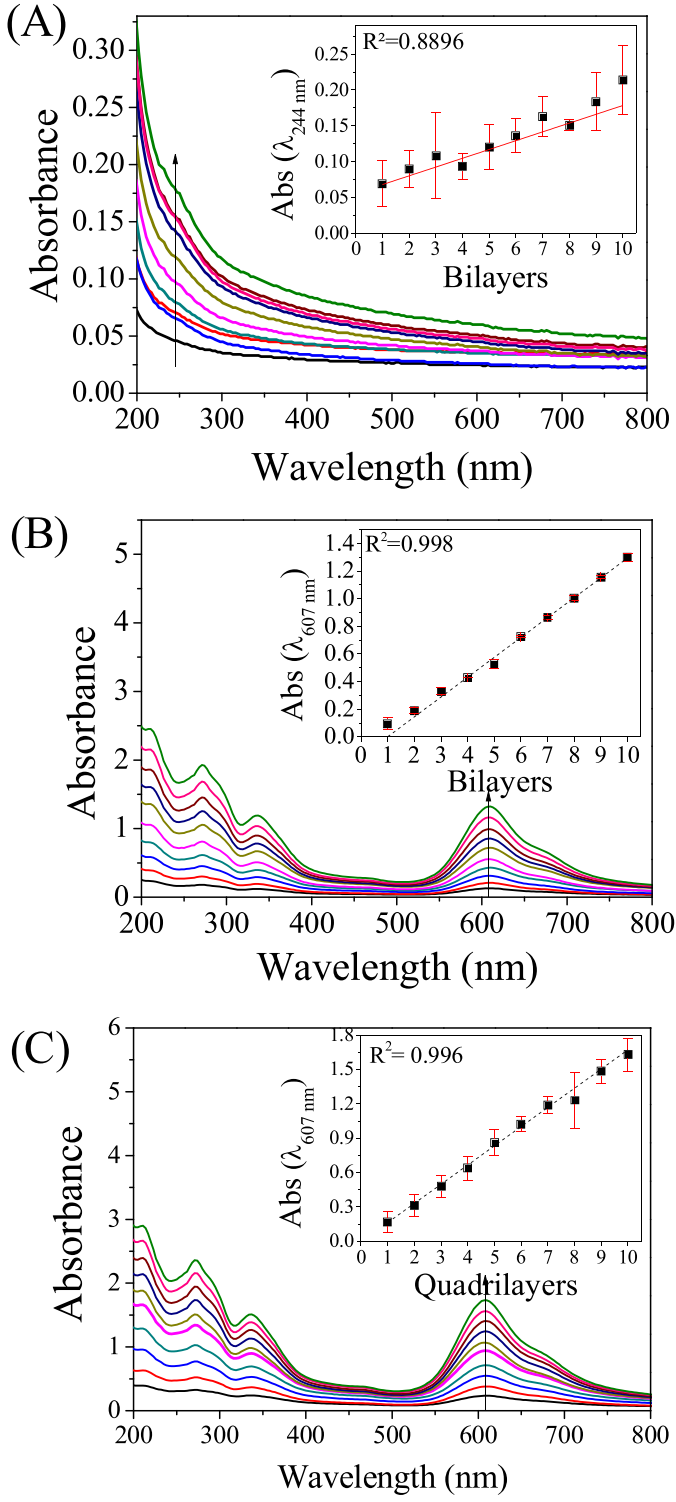

Fig. 2. LbL film growths monitored by UV-vis absorption spectra of (A) $\left(\mathrm{PEI} / \mathrm{Na}^{+} \mathrm{MMT}\right)_{10}$, (B) (PEI/NiTsPc $)_{10}$, and (C) (PEI/Na+ MMT/PEI/NiTsPc $)_{10}$ deposited in quartz substrates. Inset: relationship between the absorbance and number of deposited layers.

$336 \mathrm{~nm}$ from $\pi-\pi^{*}$ transition in the macrocyclic ring of phthalocyanine [36], and Q band at $608 \mathrm{~nm}$ (dimeric) and a shoulder at $663 \mathrm{~nm}$ (monomeric) due to the HOMO-LUMO orbital transitions due to the interactions between the central metal and axial ligands in the phthalocyanine structure [36]. The inset presents the linear relationship between the absorbance (at $607 \mathrm{~nm}$ for both films containing NiTsPc films) and the number of layers deposited, indicating these films are grown in a controlled way in terms of thickness/bilayer (or /quadri-layer) at nanoscale.

The interaction between each material in the composition of the LbL films was investigated by FTIR. Fig. 3A shows the spectra of LbL film of 10 bilayers of (PEI/Na+ $\left.{ }^{+} \mathrm{MMT}\right)$ along with spectra of pure PEI and $\mathrm{Na}^{+} \mathrm{MMT}$ in cast films. The characteristic clay bands at 467 , 525 and $1047 \mathrm{~cm}^{-1}$ attributed to $\mathrm{Si}-\mathrm{O}$ and $\mathrm{Al}-\mathrm{O}$ deformations, and Si-O stretching, respectively [35], exhibited a red shift after the LbL film formation to 462,522 and $1042 \mathrm{~cm}^{-1}$. PEI bands at 1580 and $1483 \mathrm{~cm}^{-1}$ assigned to $\mathrm{N}-\mathrm{H}$ and $\mathrm{C}-\mathrm{H}$ bending were also found in the LbL film with small changes in position and lower relative intensities. $\mathrm{Na}^{+} \mathrm{MMT}$ clay forms negative charges on its basal plane 
(A)

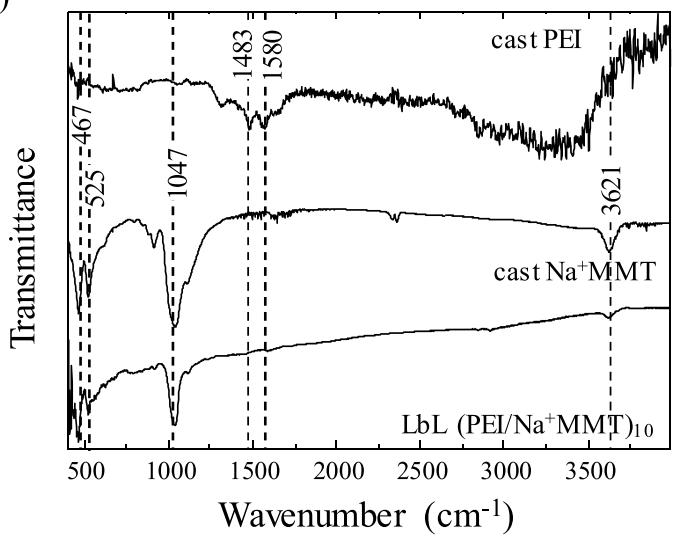

(B)

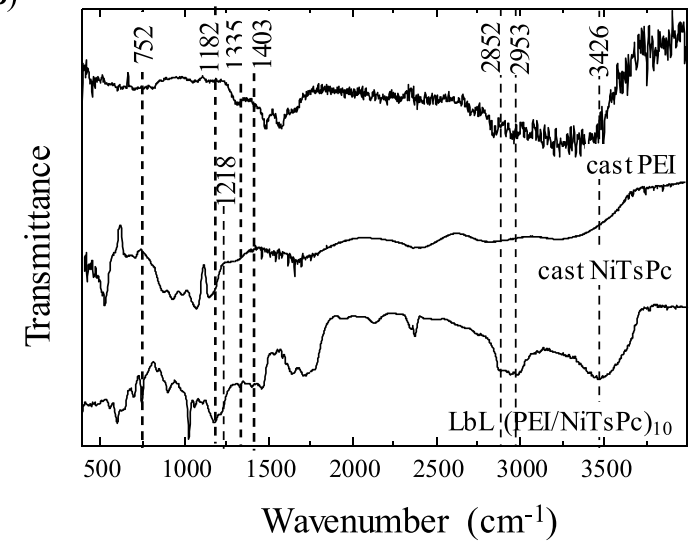

(C)
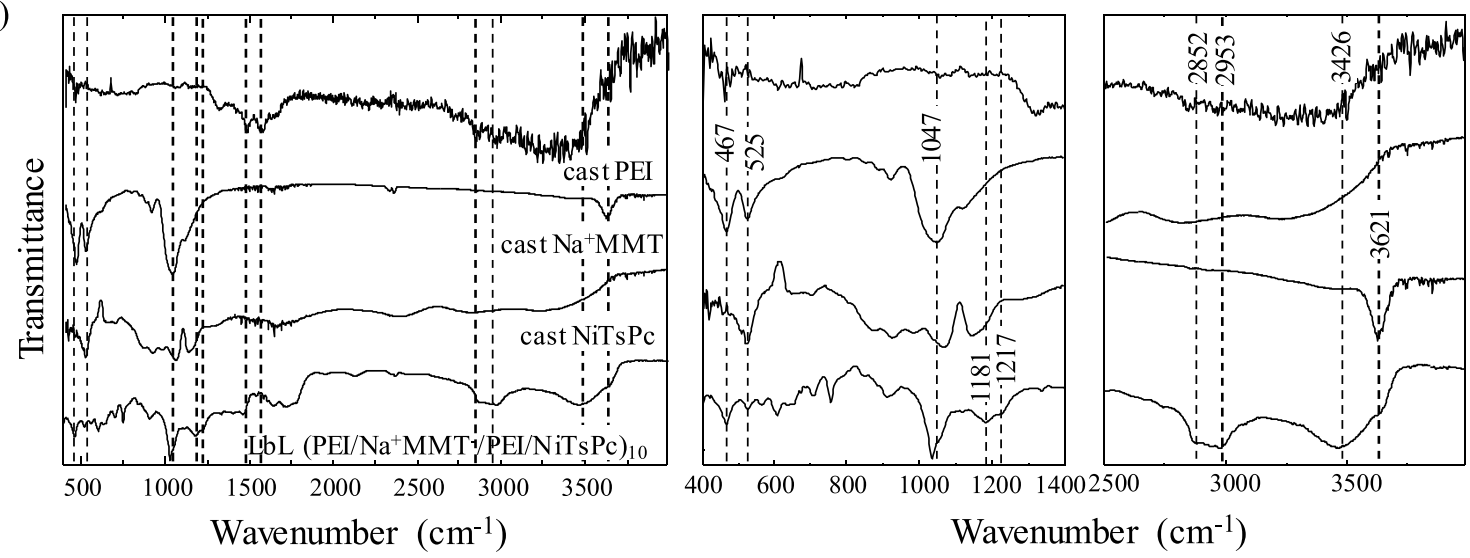

Fig. 3. FTIR spectra of $(\mathrm{A})\left(\mathrm{PEI} / \mathrm{Na}^{+} \mathrm{MMT}\right)_{10}$, (B) $(\mathrm{PEI} / \mathrm{NiTsPc})_{10}$, and $(\mathrm{C})\left(\mathrm{PEI} / \mathrm{Na}^{+} \mathrm{MMT} / \mathrm{PEI} / \mathrm{NiTsPc}\right)_{10}$ in comparison to cast films of pure materials on silicon substrates.

due to the isomorphic substitution of $\mathrm{Al}^{+}, \mathrm{Si}^{+}$and $\mathrm{Mg}^{+}[37,38]$. The edges are occupied by octahedral $\mathrm{Al}-\mathrm{OH}$ and tetrahedral $\mathrm{Si}-\mathrm{OH}$ and the ionization or protonation of these sites are dependent on the $\mathrm{pH}$ of the suspension [37], being positively charged below and negatively charged above $\mathrm{pH} 6.5$ [38]. Thus at our working $\mathrm{pH}$, both basal plane and edges are negatively charged and it is expected an electrostatic attraction with positively charged PEI. Some neutral sites can also contribute by Van der Waals forces [39].

For (PEI/NiTsPc) $)_{10}$ film (Fig. 3B), the main vibrational bands appear at $\sim 3400 \mathrm{~cm}^{-1}$ due to the stretching mode of $\mathrm{NH}_{3}{ }^{+}$from PEI, and overlapped bands in $2800-2900 \mathrm{~cm}^{-1}$ region assigned to $\mathrm{C}-\mathrm{H}$ stretching vibrations. Additionally, NiTsPc bands could be found at $752 \mathrm{~cm}^{-1}$ (out-of-plane $\mathrm{C}-\mathrm{H}$ ring stretching), $1182 \mathrm{~cm}^{-1}$ ( $\mathrm{S}=0$ symmetric stretching), and $1403 \mathrm{~cm}^{-1}$ (isoindole stretching) $[25,40]$. Special attention to the band at $1182 \mathrm{~cm}^{-1}$, which splits to two stronger bands at 1180 and $1218 \mathrm{~cm}^{-1}$ in the LbL film. Additionally, the band at $1041 \mathrm{~cm}^{-1}$ due to $-\mathrm{SO}_{3}$ stretching in the cast NiTsPc appears as a stronger peak shifted to $1033 \mathrm{~cm}^{-1}$ in the LbL (PEI/NiTsPc) 10 . These changes suggest a supramolecular level interaction via formation of salt bridges of $\mathrm{SO}_{3}-\mathrm{NH}_{3}$, which act as binding forces between PEI and NiTsPc to the LbL film formation $[40,41]$. Salt bridge is an interaction between two groups of opposite charge in which at least one pair of heavy atoms is within a hydrogen bonding distance [42]. In other words, it can be understood as a combination of electrostatic interaction and Hydrogen bonding, in this case between $\mathrm{O}$ atom of sulfonic group from NiTsPc and $\mathrm{H}$ atom from amine group from PEI. For the quadri-layer architecture of $\left(\mathrm{PEI} / \mathrm{Na}^{+} \mathrm{MMT} / \mathrm{PEI} / \mathrm{NiTsPc}\right)_{10}$ (Fig. 3C), the spectrum exhibits the superposition of 3360 and $3426 \mathrm{~cm}^{-1}$ (symmetric and asymmetric stretching $\mathrm{N}-\mathrm{H}$ from $\mathrm{PEI}$ ) bands and a shoulder at
$3621 \mathrm{~cm}^{-1}$ from clay (Si-OH stretching) [30]. Clay bands at 467 and $525 \mathrm{~cm}^{-1}$ ( $\mathrm{Si}-\mathrm{O}$ and $\mathrm{Al}-\mathrm{O}$ deformations) demonstrated a shift to lower energies ( 464 and $522 \mathrm{~cm}^{-1}$ ), indicating that these polar groups can be involved in the interaction with the equally polar amine groups from PEI, which has red shifted from $\mathrm{N}-\mathrm{H}$ bending (from 1580 to $1543 \mathrm{~cm}^{-1}$ ). Also, the separated bands at 1181 and $1217 \mathrm{~cm}^{-1}$, which are attributed to the $\mathrm{SO}_{3}-\mathrm{NH}_{3}$ bridge between sulfonic groups from the phthalocyanine and the amine groups from the polyelectrolyte [41]. All this findings are an indicative of supramolecular-level interaction between the multilayers formation in the quadri-layer structure.

Fig. 4 shows the optical images for each LbL film and the arrays indicate the spot from where the Raman spectra were recorded with spatial resolution close to $1 \mu \mathrm{m}^{2}$. In a general way, at micrometer scale the optical images reveal a non-uniform surface of the films in terms of morphology, while the Raman spectra reveal the same in terms of spatial distribution of the components of the films (usually we have aggregates composed mainly by clay or by NiTsPc). However, it is interesting this structure at microscale does not affect the reproducibility of the results in the sensing experiments, as shown in Sections 3.2 and 3.3. Specifically speaking, Fig. 4A depicts the optical micrography of $\left(\mathrm{PEI} / \mathrm{Na}^{+} \mathrm{MMT}\right)_{5}$ film on silicon substrate showing large clay aggregates, which was characterized by Raman spectrum dominated by Si signal, as expected for clay samples (low Raman scattering cross section) [30]. On the other hand, NiTsPc signal dominates the Raman spectrum when recorded with $632.8 \mathrm{~nm}$ laser line, which is the case in Fig. $4 \mathrm{~B}$ and C. This effect is called resonance Raman scattering, whose origin is in the resonance between the $632.8 \mathrm{~nm}$ excitation laser and the NiTsPc electronic absorption (Fig. $2 \mathrm{~B}$ and $\mathrm{C}$ ). (PEI/NiTsPc) $)_{5}$ films 
(A)
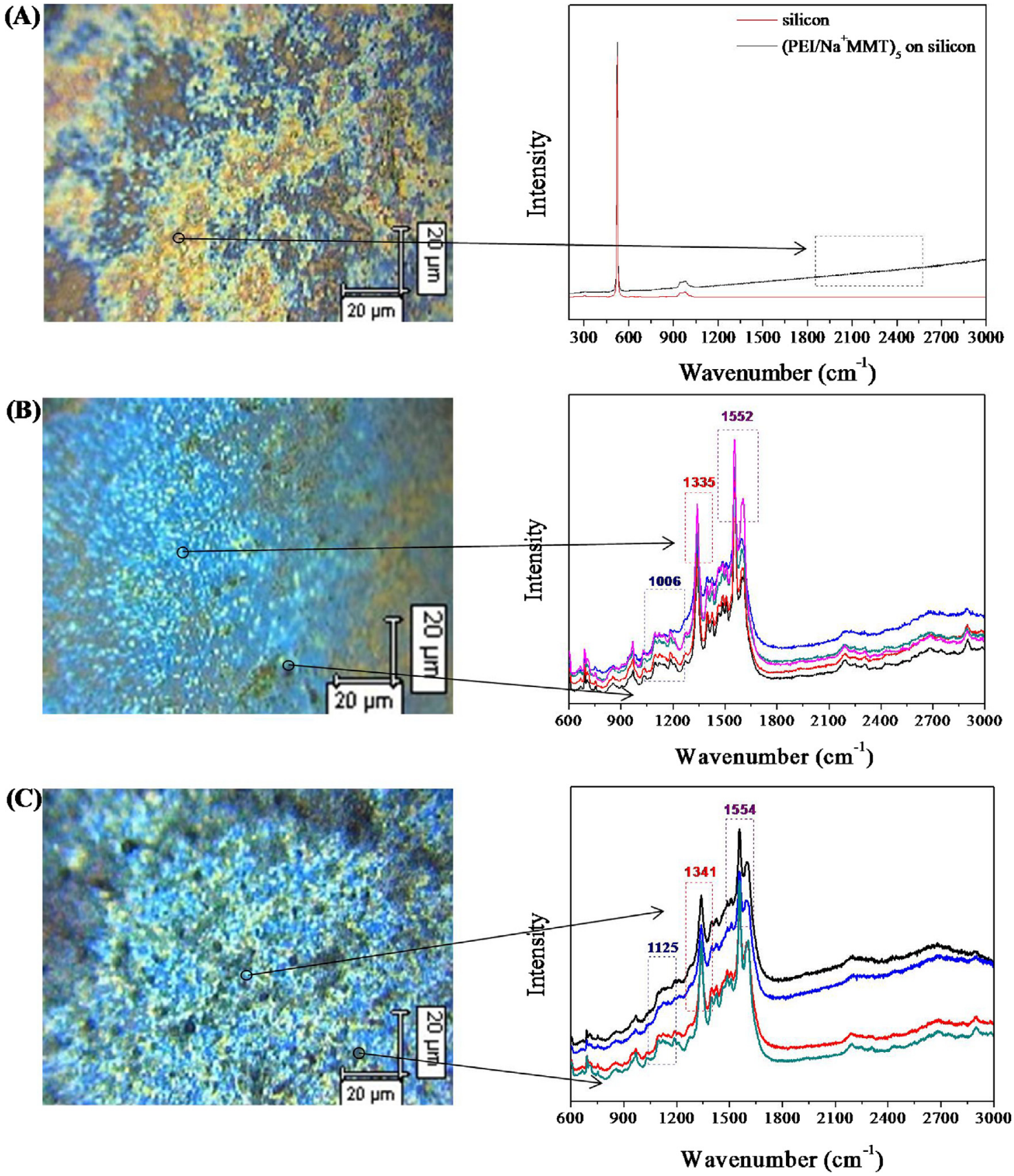

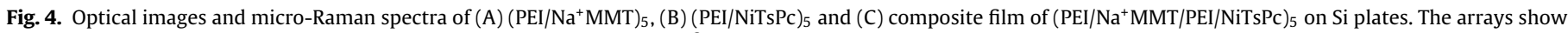
the spot form where the spectra were collected (spatial resolution ca. $1 \mu \mathrm{m}^{2}$ ). Laser line at $632.8 \mathrm{~nm}$.

exhibited two different points with some aggregates with higher amount of NiTsPc than others (Fig. 4B). NiTsPc bands appeared at 1335 and $1552 \mathrm{~cm}^{-1}$, corresponding to the phthalocyanine (pyrrole stretching) and another one at $1006 \mathrm{~cm}^{-1}$ attributed to $\mathrm{SO}_{3}$ group from NiTsPc. The nanocomposite film of (PEI/Na $\left.{ }^{+} \mathrm{MMT} / \mathrm{PEI} / \mathrm{NiTsPc}\right)_{5}$ (Fig. 4C) presented the characteristic bands of NiTsPc shifted to higher energies: pyrrole stretching (from 1335 to $1341 \mathrm{~cm}^{-1}$ and from 1552 to $1554 \mathrm{~cm}^{-1}$ ) and sulfonated groups stretching (from 1006 to $1125 \mathrm{~cm}^{-1}$ ) when compared to the (PEI/NiTsPc) $)_{5}$ film, indicating the possibility of stronger interaction between the materials when in the quadri-layer structured film.

Topographical (3D) and phase (2D) images obtained with AFM of three films structures, in a $25 \mu \mathrm{m}^{2}$ window are depicted in Fig. 5. From topographic images the calculated root mean square
(RMS) roughness values for $\left(\mathrm{PEI} / \mathrm{Na}^{+} \mathrm{MMT}\right)_{5},(\mathrm{PEI} / \mathrm{NiTsPc})_{5}$, and $\left(\mathrm{PEI} / \mathrm{Na}^{+} \mathrm{MMT} / \mathrm{PEI} / \mathrm{NiTsPc}\right)_{5}$ films are $18.3 \pm 2.5 \mathrm{~nm}, 58.1 \pm 14.2 \mathrm{~nm}$, and $82.2 \pm 13.1 \mathrm{~nm}$, respectively. Phase imaging presented at the right side of Fig. 5, highlight the increase on homogeneity for quadri-layer film, if comparing to Fig. 5A and B in which the colour variation represents the difference on surface softness the map colour variation in Fig. 5C is negligible. From Fig. 4A it is possible to observe clay aggregates in the film surface that suggest the film growth is controlled by aggregation of grown grains as also observed in Fig. 5A which explain the low roughness value obtained. It is worth to note that the sum of roughness of architectures 1 and 2 is $8 \%$ lower than the architecture 3 because of synergistic effect that can lead to an enhance on sensing system as will be discussed. 

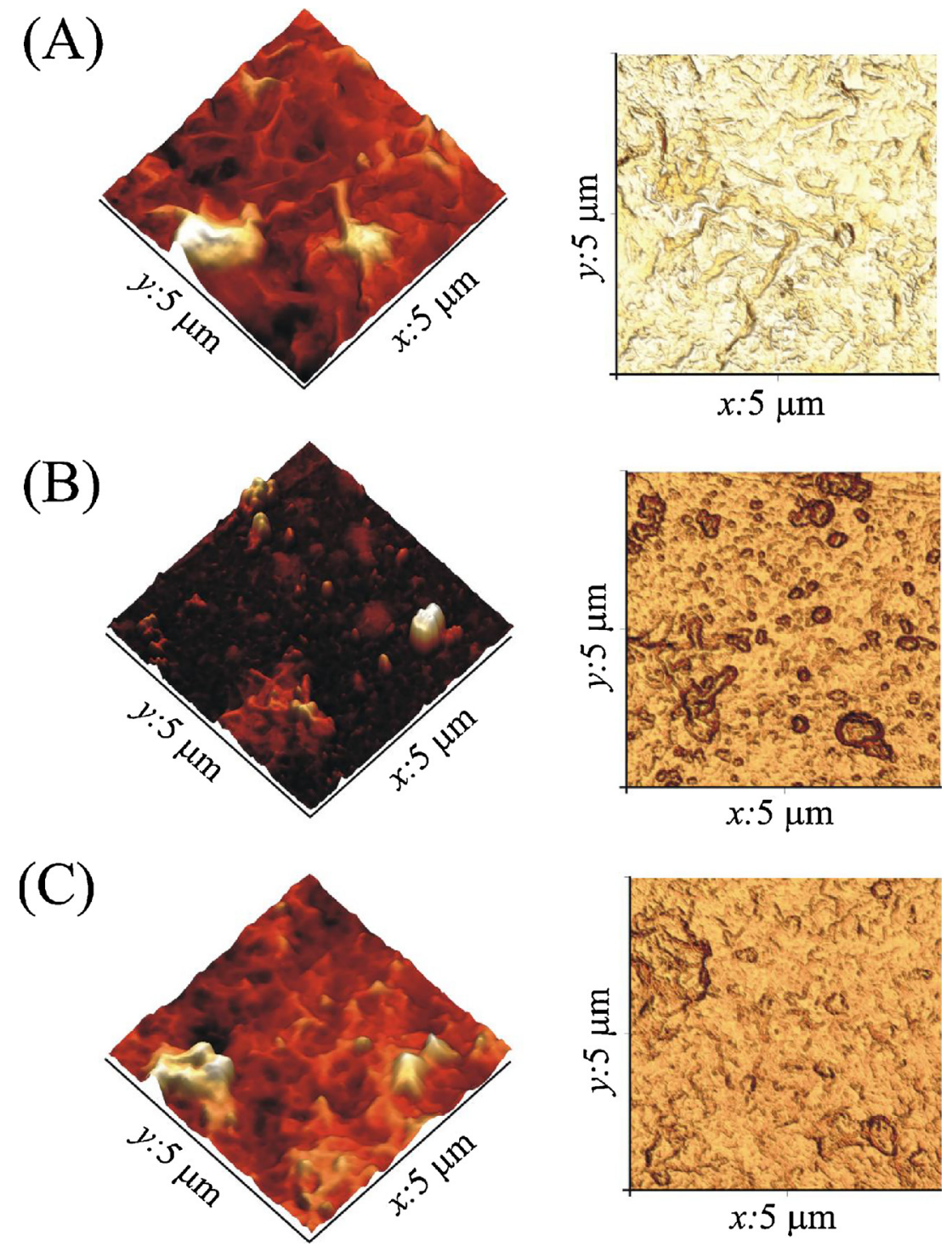

Fig. 5. 3D and 2D tapping mode AFM images of $(\mathrm{A})\left(\mathrm{PEI} / \mathrm{Na}^{+} \mathrm{MMT}\right)_{5} \mathrm{film}$, (B) $(\mathrm{PEI} / \mathrm{NiTsPc})_{5}$ film, and $(\mathrm{C})\left(\mathrm{PEI} / \mathrm{Na}{ }^{+} \mathrm{MMT} / \mathrm{PEI} / \mathrm{NiTsPc}\right)_{5}$ film on mica substrate.

\subsection{DA detection by differential pulse voltammetry}

Fig. 6 depicts the DPV profile for detection of different concentrations of DA in $\mathrm{pH} 7.0$ phosphate buffer applying the ITO electrodes modified with the LbL films of (PEI/Na ${ }^{+} \mathrm{MMT}$ ), (PEI/NiTsPc), and (PEI/Na $\left.{ }^{+} \mathrm{MMT} / \mathrm{PEI} / \mathrm{NiTsPc}\right)$. After the first injections of DA, just one anodic peak was observed at about $+0.28 \mathrm{~V}$, which is attributed to the oxidation of dopamine to 0 dopaminoquinone (o-DQ) in a two electron oxidation process (E1 step, Eq. (1) at Fig. 7) [43,44]. Subsequently, when the amine is deprotonated, an intramolecular cyclization of $o$-DQ via $1,4-$ Michael addition leads to the production of leucodopaminechrome (LDC) $[44,45]$ by the C step (Eq. (2) in Fig. 7). LDC can experience a two-electron oxidation to form dopaminochrome (DC) $[43,44]$ (E2 step at Fig. 7 ), which can be observed at $+0.45 \mathrm{~V}$ in the same way that found by [46]. This peak appears after oxidation of the first injections of DA (see Fig. 6).

Before the DPV tests, the two architectures composed by NiTsPc were submitted to a series of voltammetric cycles until the stabilization (see Supporting information - Fig. S1). Fig. 6 exhibits the DPV results for ITO/(PEI/Na+ MMT $)_{10}$, ITO/(PEI/NiTsPc $)_{10}$, and ITO/(PEI/Na $\left.{ }^{+} \mathrm{MMT} / \mathrm{PEI} / \mathrm{NiTsPc}\right)_{10}$ electrodes, while Table 1 exhibits the analytical parameters for each one. The limit of detection (LOD) was calculated in accordance with IUPAC recommendation as follows: $3 \times \mathrm{SD} / b$, where $\mathrm{SD}$ is the standard deviation of the 10 measurements of blank and $b$ is the sensitivity determined as the slope of the calibration curve [47]. The ITO/(PEI/Na $\left.{ }^{+} \mathrm{MMT}\right)_{10}$ electrode demonstrated poor reproducibility checked by the large deviation bars and considerable low $R^{2}$ value (0.958), which can be related to uncontrolled LbL film growth (verified at Fig. 2A). Architectures containing NiTsPc presented lower potential for oxidation peak with better separation from the second oxidation peak (at $0.48 \mathrm{~V}$ ) (Fig. 6B,C). Additionally, a broader linear range was achieved from $50-600$ and from $20-600 \mu \mathrm{mol} \mathrm{L}^{-1}$ for ITO/(PEI/NiTsPc $)_{10}$ and ITO/(PEI/Na $\left.{ }^{+} \mathrm{MMT} / \mathrm{PEI} / \mathrm{NiTsPc}\right)_{10}$, respectively, and also an improved linear adjust values. The presence of NiTsPc was capable of decreasing the oxidation potential, leading to a better separation of first and second oxidation peaks. The synergistic effect from quadri-layers of (PEI/Na+ $\left.\mathrm{NMT}^{+} \mathrm{PEI} / \mathrm{NiTsPc}\right)_{10}$ provided a higher detection range and a lower LOD. Montomorillonite clays are known to its adsorption properties, however, in the $\left(\mathrm{PEI} / \mathrm{Na}^{+} \mathrm{MMT}\right)_{10}$ film, in the absence of the NiTsPc, because of its low catalytic property, the highest dopamine oxidation potential $(\mathrm{E}=0.29 \mathrm{~V})$ and a narrow linear range of detection 
(A)

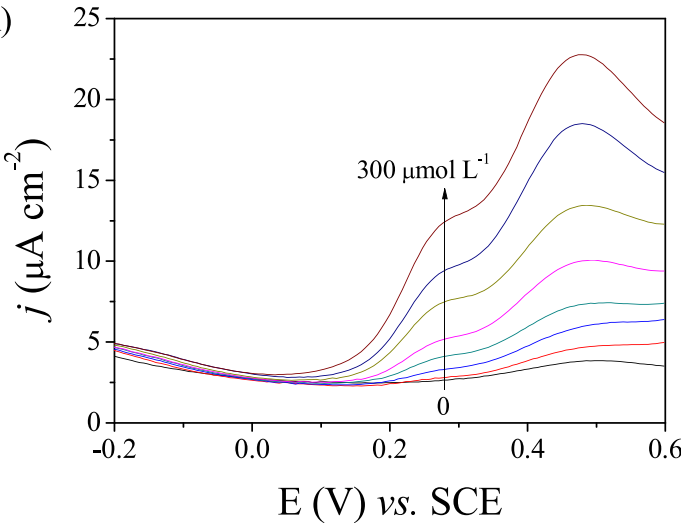

(B)

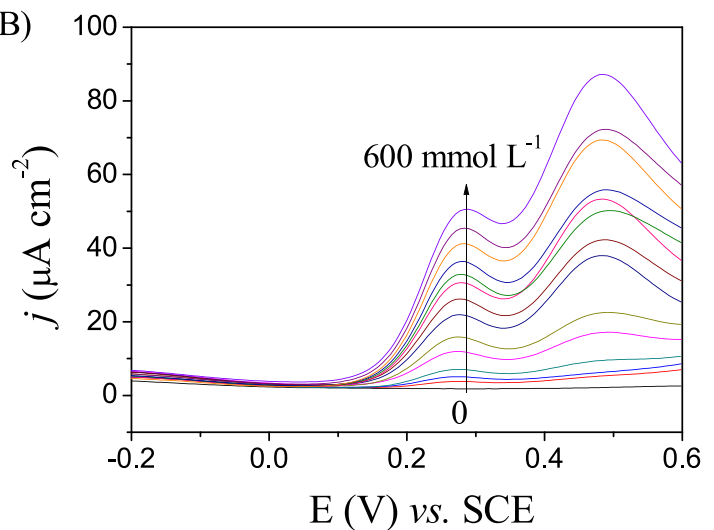

(C)

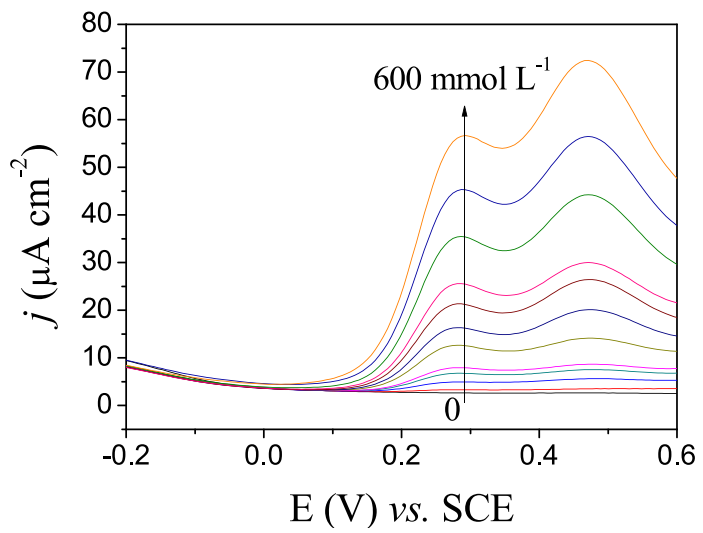

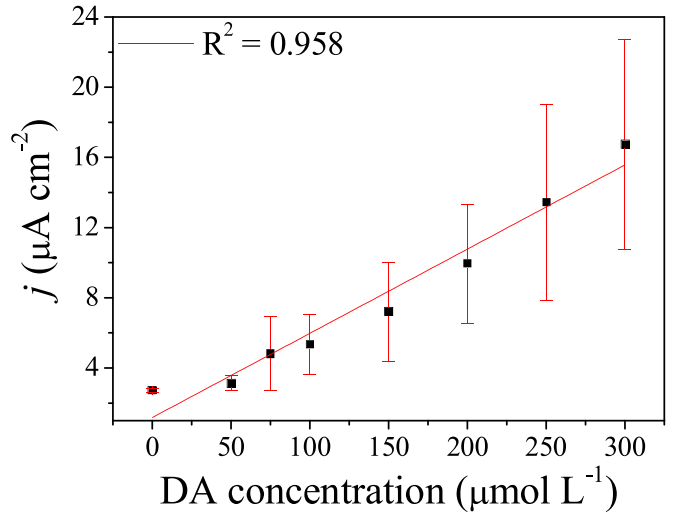

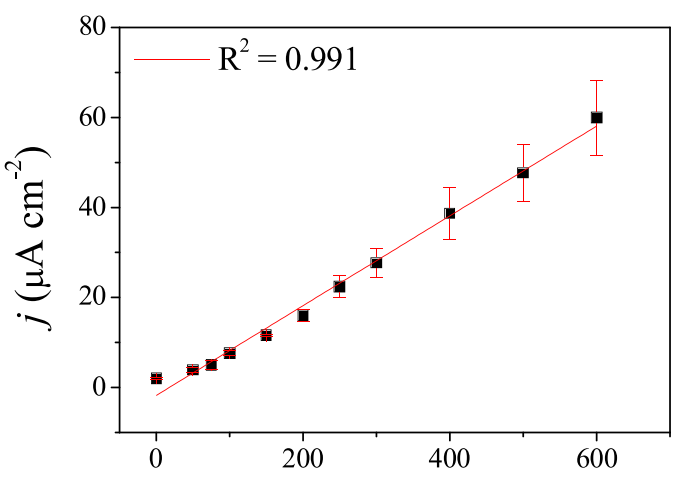

DA concentration $\left(\mu \mathrm{mol} \mathrm{L}{ }^{-1}\right)$

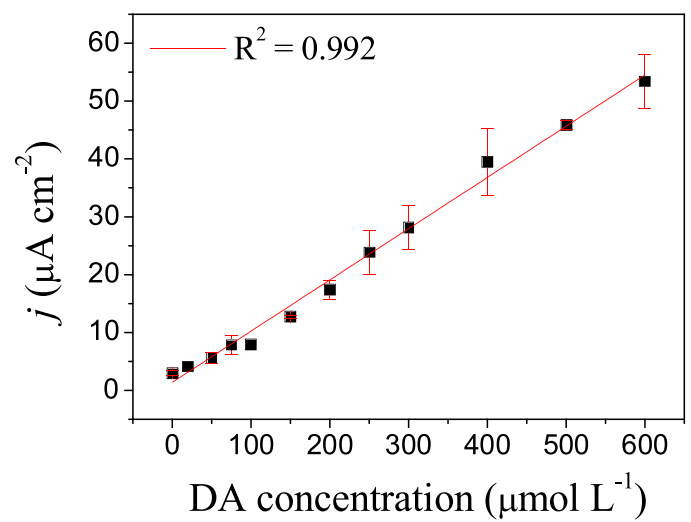

Fig. 6. DPV profile plots of anodic peak current vs. DA concentration on (A) ITO/(PEI/Na $\left.{ }^{+} \mathrm{MMT}\right)$, (B) ITO/(PEI/NiTSPc), and (C) ITO/(PEI/Na $\left.{ }^{+} \mathrm{MMT} / \mathrm{PEI} / \mathrm{NiTsPc}\right)_{5}$ electrodes in $0.1 \mathrm{~mol} \mathrm{~L}^{-1} \mathrm{pH} 7.0$ phosphate buffer.

Table 1

Analytical parameters for the three LbL architectures tested for DA detection.

\begin{tabular}{|c|c|c|c|c|c|}
\hline Electrode & $\mathrm{E}_{\mathrm{pa}}(\mathrm{V})$ & Sensitivity $\left(\mu \mathrm{Acm}{ }^{-2}\right)\left(\mu \mathrm{mol} \mathrm{L}^{-1}\right)^{-1}$ & Linear range $\left(\mu \mathrm{mol} \mathrm{L}^{-1}\right)$ & $R^{2}$ & $\operatorname{LOD}\left(\mu \mathrm{mol} \mathrm{L}^{-1}\right)$ \\
\hline $\mathrm{ITO} /\left(\mathrm{PEI} / \mathrm{Na}^{+} \mathrm{MMT}\right)_{10}$ & 0.29 & $5.38 \times 10^{-2}$ & $50-300$ & 0.958 & 2.58 \\
\hline ITO/(PEI/NiTsPc) ${ }_{10}$ & 0.28 & $9.42 \times 10^{-2}$ & $50-600$ & 0.991 & 1.71 \\
\hline ITO $/\left(\mathrm{PEI} / \mathrm{Na}^{+} \mathrm{MMT} / \mathrm{PEI} / \mathrm{NiTsPc}\right)_{10}$ & 0.28 & $7.33 \times 10^{-2}$ & $20-600$ & 0.992 & 1.39 \\
\hline
\end{tabular}

(50-300 $\mu \mathrm{mol} \mathrm{L}^{-1}$ ) were observed, and also a relatively high LOD of $2.58 \mu \mathrm{mol} \mathrm{L}{ }^{-1}$. Due to the great catalytic activity towards dopamine oxidation, the (PEI/NiTsPc) 10 film exhibited LOD of $1.71 \mu \mathrm{mol} \mathrm{L}^{-1}$ and a linear range of $50-600 \mu \mathrm{mol} \mathrm{L}^{-1}$. When $\mathrm{Na}^{+} \mathrm{MMT}$ and NiTsPc are present in the same film architecture composing (PEI/Na $\left.{ }^{+} \mathrm{MMT} / \mathrm{PEI} / \mathrm{NiTsPc}\right)_{10}$ film, the sensor was capable of decrease the $\operatorname{LOD}\left(1.39 \mu \mathrm{mol} \mathrm{L}^{-1}\right)$ and increase the dynamic range of the sensor adding up the absorption capacity of clay and catalytic activity from phthalocyanines. This LbL structure was then applied to the DPV tests in the presence of the common AA and UA interferents.

\subsection{DA detection in the presence of $U A$ and $A A$}

The interference of AA and UA represents a major problem for the electrochemical detection of DA in real samples because of the similar oxidation peaks resulting in an overlapped voltammetric response. Also, the $\mathrm{AA}$ is present in vivo at concentrations of 100-1000-fold higher than the DA concentrations [6,48]. Fig. 8A 
<smiles>[NH3+]CCc1ccc(O)c(O)c1</smiles>

DA<smiles>[15NH2+]CCC1=CC(=O)C(=O)C=C1</smiles>

$o-\mathrm{DQ}$<smiles>[NH3+]CCC1=CC(=O)C(=O)C=C1</smiles>

$o-\mathrm{DQ}$

LDC<smiles>Oc1cc2c(cc1O)NCC2</smiles>

LDC<smiles>O=C1C=C2CC([18O][PH2+])=NC2=CC1O</smiles>

DC

Fig. 7. General mechanism of the electrochemical behavior of DA. "E" denotes the electrochemical reactions while "C" denotes the chemical reaction.

(A)

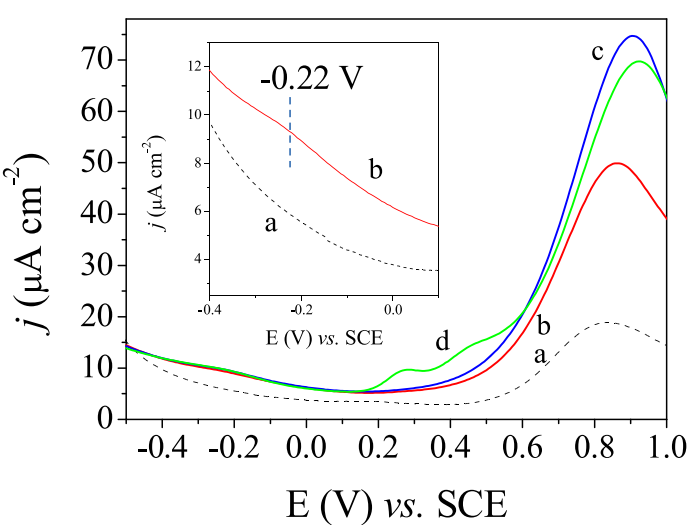

(C)

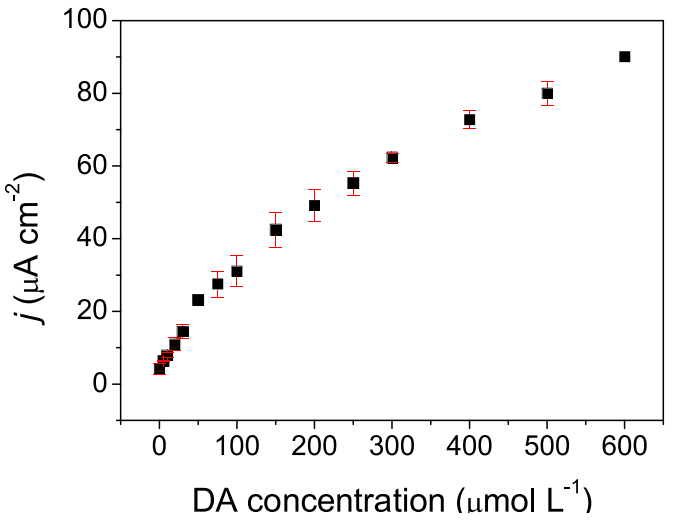

(B)

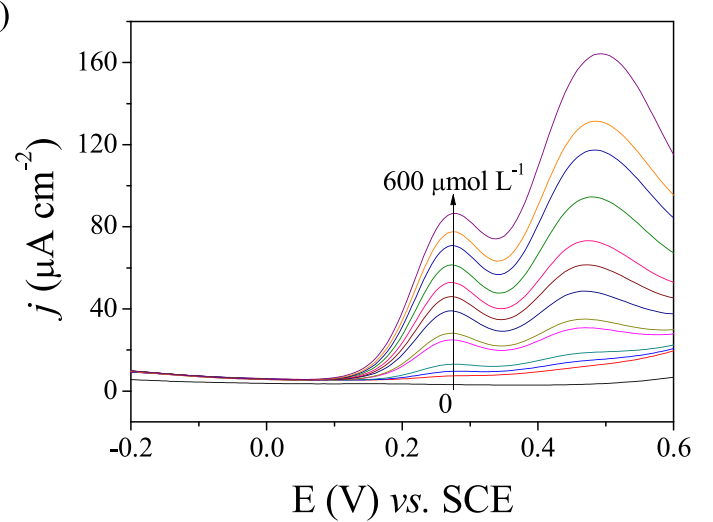

(D)

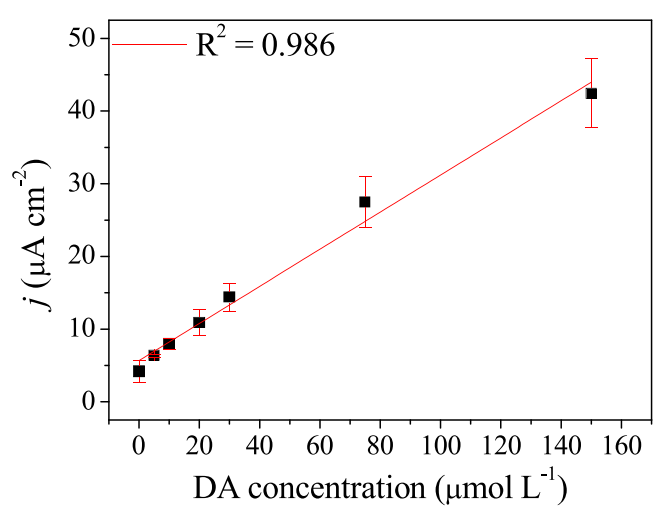

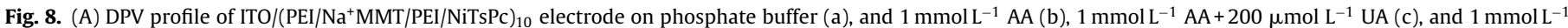

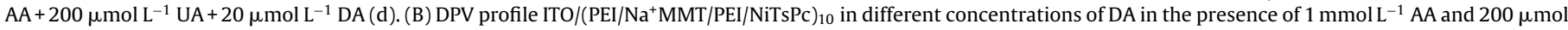
$\mathrm{L}^{-1}$ UA. (C) Relationship between current density and DA concentration from $0-600 \mu \mathrm{mol} \mathrm{L}^{-1}$, and (D) linear range from $5-150 \mu \mathrm{mol} \mathrm{L}-1$.

shows the DPV profile on ITO/(PEI/Na $\left.{ }^{+} \mathrm{MMT} / \mathrm{PEI} / \mathrm{NiTsPc}\right)_{10}$ electrode in pure phosphate buffer (curve a), in which appears an oxidation peak at $\sim 0.8 \mathrm{~V}$ from oxidation of $\mathrm{Ni}^{2+} / \mathrm{Ni}^{3+}[40]$. In the presence of $1 \mathrm{mmol} \mathrm{L}^{-1} \mathrm{AA}$ (curve $\mathrm{b}$ ), it appears a discrete oxidation peak at $-0.22 \mathrm{~V}$ and the region of $0.8 \mathrm{~V}$ has an evident increase. After injection of $200 \mu \mathrm{mol} \mathrm{L}^{-1} \mathrm{UA}$ (curve c), another increase in the oxidation peak at $0.8 \mathrm{~V}$ was observed. However, after $20 \mu \mathrm{mol} \mathrm{L}^{-1}$ DA (curve d) its oxidation peak is clearly identified at $0.28 \mathrm{~V}$. Fig. $8 \mathrm{~B}$ shows the detection of various DA concentrations in the presence of $1 \mathrm{mmol} \mathrm{L}^{-1}$ AA and $200 \mu \mathrm{mol} \mathrm{L}^{-1} \mathrm{UA}$. The oxidation peak current of DA at $0.28 \mathrm{~V}$ vs. DA concentration presented an exponential growth as shown in Fig. 8C, with the linear behavior up to $150 \mu \mathrm{mol} \mathrm{L}^{-1}$. The LOD or the sensitivity of the sensor were not harmed by the presence of the UA and $A A$, and were equal to $1.01 \mu \mathrm{mol} \mathrm{L}^{-1}$ and 0.26 $\left(\mu \mathrm{Acm}^{-2}\right)\left(\mu \mathrm{mol} \mathrm{L}^{-1}\right)^{-1}$, respectively. However, the linear range was sharpened with the film achieving the saturation quicker than when DA is pure in phosphate solution.

The ITO/(PEI/Na+ $\left.{ }^{+} \mathrm{MMT} / \mathrm{PEI} / \mathrm{NiTsPc}\right)_{10}$ results for DA detection is comparable to other electrochemical sensors in the recent literature, as summarized at Table 2. Comparing it with other LbL films onto ITO substrates, it exhibited consistent LOD value and higher range of detection. Recent publications have achieved significantly 
Table 2

Comparison of different modified electrodes for electrochemical detection of DA.

\begin{tabular}{|c|c|c|c|c|}
\hline Electrode & $\operatorname{LOD}\left(\mu \mathrm{mol} \mathrm{L}^{-1}\right)$ & Detection method & Detection range $\left(\mu \mathrm{mol} \mathrm{L}^{-1}\right)$ & Ref. \\
\hline LbL film $\left(\mathrm{SiPy}^{+} \mathrm{Cl}^{-} / \mathrm{NiTsPc}\right)_{2}{ }^{\mathrm{a}}$ & 16.8 & SWV & $10-99$ & [51] \\
\hline LbL film $(\mathrm{PAH} / \mathrm{FePc})_{5}^{\mathrm{b}}$ & 0.86 & VC & $2-97$ & [52] \\
\hline Binuclear cooper (II) modified $\mathrm{Au}^{\mathrm{C}}$ & 0.08 & DPV & $0.2-30$ & [49] \\
\hline $\mathrm{TiO}_{2}$-graphene $\mathrm{g}^{\mathrm{d}}$ & 2.0 & DPV & $5-200$ & [53] \\
\hline Pristine Graphene/GCE ${ }^{e}$ & 2.0 & Amperometry & $5-710$ & [54] \\
\hline GO/GCE & 0.27 & DPV & $1.0-15$ & [55] \\
\hline AuNPS-PTAP/GCE ${ }^{g}$ & 0.017 & DPV & $0.15-1.5$ & [50] \\
\hline ITO $/\left(\mathrm{PEI} / \mathrm{Na}^{+} \mathrm{MMT} / \mathrm{PEI} / \mathrm{NiTsPc}\right)_{5}$ & 1.0 & DPV & $5-150$ & This work \\
\hline
\end{tabular}

a ITO electrode modified with LbL film of 3-n-propylpyridinium silsesquioxane polymer $\left(\mathrm{SiPy}^{+} \mathrm{Cl}^{-}\right)$and NiTsPc.

b ITO electrode modified with LbL film of poly(allylamine) hydrochloride (PAH) and iron phthalocyanine (FePc).

c Gold electrode modified by self-assembly of Cu II complex $\mathrm{N}, \mathrm{N}$-dimethylformamide.

d Drop cast of hydrothermally prepared $\mathrm{TiO}_{2}$-graphene on GCE.

e Liquid-phase exfoliation of graphite on GCE.

f GO solution cast on NHS/EDC activated GCE electrode.

g GCE modification by electrochemically polymerization of poly(2,4,6-triaminopyrmidine (PTAP) decorated with gold nanoparticles.

Table 3

Measurements performed in human urine samples spiked with $3.0 \mu \mathrm{mol} \mathrm{L}^{-1}$ DA using the ITO/(PEI/Na+ $\left.{ }^{+} \mathrm{MMT} / \mathrm{PEI} / \mathrm{NiTsPc}\right)_{10}$ electrodes.

\begin{tabular}{llll}
\hline Sample & DA concentration $\left(\mu \mathrm{mol} \mathrm{L}^{-1}\right)$ & DA measured $\left(\mu \mathrm{mol} \mathrm{L}^{-1}\right)$ & Recovery $(\%)$ \\
\hline 1 & 3.0 & 2.82 & 94 \\
2 & 3.0 & 3.34 & 111 \\
\hline
\end{tabular}

lower LOD values, as reported by [49,50], however, it is worth to mention the complexity of the sensor device fabrication and also the narrow range of detection obtained for these devices.

\subsection{Real sample analysis}

In order to evaluate the sensor applicability in real samples, human urine without any preliminary treatment or dilution was spiked to final DA concentration of $3.0 \mu \mathrm{mol} \mathrm{L}^{-1}$. This concentration was chosen considering the dynamic range of our sensor and also because it is the upper reference level (URL) in urine $(3300 \mathrm{nmol} / 24 \mathrm{~h}$ in adult subjects [56]). DA level higher than the URL can be related with drug effects (including intravenous DA, L-dopa, antidepressants, etc.) and clinical effects (including phaeochromocytoma, carcinoid tumour and pregnancy) [56]. The results were obtained (Table 3) directly immersing the ITO/(PEI/Na $\left.{ }^{+} \mathrm{MMT} / \mathrm{PEI} / \mathrm{NiTsPc}\right)_{10}$ electrodes in the urine samples giving the DA concentration of 2.82 and $3.34 \mu \mathrm{mol} \mathrm{L}^{-1}$, a recovery of $94 \%$ and $111 \%$, respectively. These deviations of the real concentration are due to the matrix effects. Different compounds in the urine, as ascorbic acid, glucose, leucine, glycine, tartrate, citrate, bicarbonate, caffeine, etc. interfere in the background current. Additionally, urine proteins concentration is between $100-200 \mathrm{mg} / \mathrm{L}$ [57], which can adsorb in the sensor surface hampering the detection and leading to the deviations from the real concentration detection.

\section{Conclusions}

A DA sensor was successfully assembled by a simple and versatile LbL technique composed by $\mathrm{Na}^{+} \mathrm{MMT}$ and NiTsPc. A structural characterization was performed to understand the assembly of LbL film, which indicated that electrostatic interactions are the main driving force for the (PEI/Na ${ }^{+} \mathrm{MMT}$ ) film formation while the (PEI/NiTsPc) film growth was governed by the salt bridges formation. The synergistic effect between the materials in the LbL film composition allowed a better separation of the first and the second oxidation peaks of DA, a decreased LOD, and an enhanced detection range. A LOD of $1.01 \mu \mathrm{mol} \mathrm{L}^{-1}$ of DA was achieved in the presence of AA and UA. The human urine sample spiked with $3.0 \mu \mathrm{mol} \mathrm{L}^{-1}$ of DA was successfully tested showing the applicability in real analysis.

\section{Acknowledgements}

This work was supported by the São Paulo Research Foundation - FAPESP (grant 2014/15093-7, 2015/15033-6, 2016/19387, 2012/15543-7, 2013/14262-7) and CNPq.

\section{Appendix A. Supplementary data}

Supplementary material related to this article can be found, in the online version, at doi:https://doi.org/10.1016/j.apsusc.2017.12. 117

\section{References}

[1] K. Jackowska, P. Krysinski, New trends in the electrochemical sensing of dopamine, Anal. Bioanal. Chem. 405 (2013) 3753-3771.

[2] R.P. da Silva, A.W.O. Lima, S.H.P. Serrano, Simultaneous voltammetric detection of ascorbic acid, dopamine and uric acid using a pyrolytic graphite electrode modified into dopamine solution, Anal. Chim. Acta 612 (2008) 89-98.

[3] D. Zhao, G. Yu, K. Tian, C. Xu, A highly sensitive and stable electrochemical sensor for simultaneous detection towards ascorbic acid, dopamine, and uric acid based on the hierarchical nanoporous PtTi alloy, Biosens. Bioelectron. 82 (2016) 119-126.

[4] S.-J. Li, J.-Z. He, M.-J. Zhang, R.-X. Zhang, X.-L. Lv, S.-H. Li, H. Pang, Electrochemical detection of dopamine using water-soluble sulfonated graphene, Electrochim. Acta 102 (2013) 58-65.

[5] J. Hou, C. Xu, D. Zhao, J. Zhou, Facile fabrication of hierarchical nanoporous AuAg alloy and its highly sensitive detection towards dopamine and uric acid, Sens. Actuators B: Chem. 225 (2016) 241-248.

[6] N.G. Mphuthi, A.S. Adekunle, O.E. Fayemi, L.O. Olasunkanmi, E.E. Ebenso, Phthalocyanine doped metal oxide nanoparticles on multiwalled carbon nanotubes platform for the detection of dopamine, Sci. Rep. 7 (2017) 43181.

[7] A. Pandikumar, G.T.S. How, T.P. See, F.S. Omar, S. Jayabal, K.Z. Kamali, N. Yusoff, A. Jamil, R. Ramaraj, S.A. John, H.N. Lim, N.M. Huang, Graphene and its nanocomposite material based electrochemical sensor platform for dopamine, RSC Adv. 4 (2014) 63296-63323.

[8] M. Sajid, M.K. Nazal, M. Mansha, A. Alsharaa, S.M.S. Jillani, C. Basheer, Chemically modified electrodes for electrochemical detection of dopamine in the presence of uric acid and ascorbic acid: A review, TrAC Trends Anal. Chem. 76 (2016) 15-29.

[9] S. Liu, J. Yan, G. He, D. Zhong, J. Chen, L. Shi, X. Zhou, H. Jiang, Layer-by-layer assembled multilayer films of reduced graphene oxide/gold nanoparticles for the electrochemical detection of dopamine, J. Electroanal. Chem. 672 (2012) 40-44.

[10] A. Daniel Arulraj, A. Arunkumar, M. Vijayan, K. Balaji Viswanath, V.S. Vasantha, A simple route to develop highly porous nano polypyrrole/reduced graphene oxide composite film for selective determination of dopamine, Electrochimica Acta. 206 (2016) 77-85.

[11] X.-H. Cao, L.-X. Zhang. W.-P. Cai, Y.-O. Li, Amperometric sensing of dopamine using a single-walled carbon nanotube covalently attached to a conical glass micropore electrode, Electrochem. Commun. 12 (2010) 540-543.

[12] M. Zhang, K. Gong, H. Zhang, L. Mao, Layer-by-layer assembled carbon nanotubes for selective determination of dopamine in the presence of ascorbic acid, Biosens. Bioelectron. 20 (2005) 1270-1276.

[13] N. Li, E. Zheng, X. Chen, S. Sun, C. You, Y. Ruan, X. Weng, Layer-by-layer assembled multilayer films of nitrogen-doped graphene and polyethylenimine for selective sensing of dopamine, Int. J. Electrochem. Sci. 8 (2013) 6524-6534. 
[14] X. Weng, O. Cao, L. Liang, J. Chen, C. You, Y. Ruan, H. Lin, L. Wu, Simultaneous determination of dopamine and uric acid using layer-by-layer graphene and chitosan assembled multilayer films, Talanta. 117 (2013) 359-365.

[15] P. Pang, F. Yan, H. Li, H. Li, Y. Zhang, H. Wang, Z. Wu, W. Yang, Graphene quantum dots and nafion composite as an ultrasensitive electrochemical sensor for the detection of dopamine, Anal. Methods. 8 (2016) 4912-4918.

[16] C.M. Miyazaki, T.P. Pereira, D.B.T. Mascagni, M.L. de Moraes, M. Ferreira, Monoamine oxidase B layer-by-layer film fabrication and characterization toward dopamine detection, Mater. Sci. Eng.: C 58 (2016) 310-315.

[17] D. Uzun, A. Balaban Gündüzalp, E. Hasdemir, Selective determination of dopamine in the presence of uric acid and ascorbic acid by $\mathrm{N}, \mathrm{N}^{\prime}$-bis(indole-3-carboxaldimine)-1,2-diaminocyclohexane thin film modified glassy carbon electrode by differential pulse voltammetry, J. Electroanal. Chem. 747 (2015) 68-76

[18] J.A. Duro, G. de la Torre, J. Barberá, J.L. Serrano, T. Torres, Synthesis and liquid-crystal behavior of metal-free and metal-containing phthalocyanines substituted with long-chain amide groups, Chem. Mater. 8 (1996) 1061-1066.

[19] B. Ceken, M. Kandaz, A. Koca, Electrochemical metal-ion sensors based on a novel manganese phthalocyanine complex, Synth. Met. 162 (2012) 1524-1530.

[20] S. Chakane, A. Gokarna, S.V. Bhoraskar, Metallophthalocyanine coated porous silicon gas sensor selective to NO2, Sens. Actuators B: Chem. 92 (2003) 1-5.

[21] K.-C. Ho, Y.-H. Tsou, Chemiresistor-type NO gas sensor based on nickel phthalocyanine thin films, Sens. Actuators B: Chem. 77 (2001) 253-259.

[22] M. Pontie, H. Lecture, F. Bedioui, Improvement in the performance of a nickel complex-based electrochemical sensor for the detection of nitric oxide in solution, Sens. Actuators B: Chem. 56 (1999) 1-5.

[23] P. Skladal, M. Mascini, Sensitive detection of pesticides using amperometric sensors based on cobalt phthalocyanine-modified composite electrodes and immobilized cholinesterases, Biosens. Bioelectron. 7 (1992) 335-343.

[24] W. Siangproh, O. Chailapakul, R. Laocharoensuk, J. Wang, Microchip capillary electrophoresis/electrochemical detection of hydrazine compounds at a cobalt phthalocyanine modified electrochemical detector, Talanta 67 (2005) 903-907.

[25] H. Xu, J. Xiao, L. Yan, L. Zhu, B. Liu, An electrochemical sensor for selective detection of dopamine based on nickel tetrasulfonated phthalocyanine functionalized nitrogen-doped graphene nanocomposites, J. Electroanal. Chem. 779 (2016) 92-98.

[26] G. Decher, Fuzzy nanoassemblies: toward layered polymeric multicomposites, Science 277 (1997) 1232-1237.

[27] C. Aguzzi, P. Cerezo, C. Viseras, C. Caramella, Use of clays as drug delivery systems: possibilities and limitations, Appl. Clay Sci. 36 (2007) 22-36.

[28] A. de Barros, M. Ferreira, C.J.L. Constantino, J.R.R. Bortoleto, M. Ferreira, Synergy between polyaniline and omt clay mineral in langmuir-blodgett films for the simultaneous detection of traces of metal ions, ACS Appl. Mater Interfaces 7 (2015) 6828-6834.

[29] U. Guth, S. Brosda, J. Schomburg, Applications of clay minerals in sensor techniques, Appl. Clay Sci. 11 (1996) 229-236.

[30] A. de Barros, M. Ferreira, C.J.L. Constantino, M. Ferreira, Nanocomposites based on LbL films of polyaniline and sodium montmorillonite clay, Synth. Met. 197 (2014) 119-125.

[31] M.M. Hasani-Sadrabadi, S.H. Emami, R. Ghaffarian, H. Moaddel, Nanocomposite membranes made from sulfonated poly(ether ether ketone) and montmorillonite clay for fuel cell applications, Energy Fuels 22 (2008) 2539-2542.

[32] C. Mousty, Sensors and biosensors based on clay-modified electrodes-new trends, Appl. Clay Sci. 27 (2004) 159-177.

[33] G. Decher, J.D. Hong, J. Schmitt, Buildup of ultrathin multilayer films by a self-assembly process: III. Consecutively alternating adsorption of anionic and cationic polyelectrolytes on charged surfaces, Thin Solid Films 210-211 (Part 2) (1992) 831-835.

[34] Y. Umemura, Y. Onodera, A. Yamagishi, Layered structure of hybrid films of an alkylammonium cation and a clay mineral as prepared by the Langmuir-Blodgett method, Thin Solid Films 426 (2003) 216-220.

[35] A. de Barros, C.J.L. Constantino, N.C. da Cruz, J.R.R. Bortoleto, M. Ferreira, High performance of electrochemical sensors based on LbL films of gold nanoparticles, polyaniline and sodium montmorillonite clay mineral for simultaneous detection of metal ions, Electrochimica Acta. 235 (2017) 700-708.

[36] C.C. Leznoff, A.B.P. Lever, Phthalocyanines, Properties and Applications, Wiley-VCH, 1989 (Accessed 3 August 2016) http://eu.wiley.com/WileyCDA/ WileyTitle/productCd-0471187208.html.
[37] Y. Song, D.A. Hagen, S. Qin, K.M. Holder, K. Falke, J.C. Grunlan, Edge charge neutralization of clay for improved oxygen gas barrier in multilayer nanobrick wall thin films, ACS Appl. Mater. Interfaces. 8 (2016) 34784-34790.

[38] D.A. Hagen, L. Saucier, J.C. Grunlan, Controlling effective aspect ratio and packing of clay with $\mathrm{pH}$ for improved gas barrier in nanobrick wall thin films, ACS Appl. Mater. Interfaces 6 (2014) 22914-22919.

[39] N.A. Kotov, T. Haraszti, L. Turi, G. Zavala, R.E. Geer, I. Dekany, J.H. Fendler, Mechanism of and defect formation in the self-assembly of polymeric polycation- montmorillonite ultrathin films, J. Am. Chem. Soc. 119 (1997) 6821-6832.

[40] W.S. Alencar, F.N. Crespilho, M.V.A. Martins, V. Zucolotto, O.N. Oliveira Jr., W.C. Silva, Synergistic interaction between gold nanoparticles and nickel phthalocyanine in layer-by-layer (LbL) films: evidence of constitutional dynamic chemistry (CDC), Phys. Chem. Chem. Phys. 11 (2009) 5086.

[41] V. Zucolotto, M. Ferreira, M.R. Cordeiro, C.J.L. Constantino, D.T. Balogh, A.R. Zanatta, W.C. Moreira, O.N. Oliveira, Unusual interactions binding iron tetrasulfonated phthalocyanine and poly(allylamine hydrochloride) in layer-by-layer films, J. Phys. Chem. B 107 (2003) 3733-3737.

[42] J.E. Donald, D.W. Kulp, W.F. DeGrado, Salt bridges: geometrically specific, designable interactions, Proteins: Struct. Funct. Bioinform. 79 (2011) 898-915.

[43] N.J. Ke, S.-S. Lu, S.-H. Cheng, A strategy for the determination of dopamine at a bare glassy carbon electrode: $p$-phenylenediamine as a nucleophile Electrochem. Commun. 8 (2006) 1514-1520.

[44] Y. Li, M. Liu, C. Xiang, Q. Xie, S. Yao, Electrochemical quartz crystal microbalance study on growth and property of the polymer deposit at gold electrodes during oxidation of dopamine in aqueous solutions, Thin Solid Films 497 (2006) 270-278.

[45] D. Yuan, X. Yuan, S. Zhou, W. Zou, T. Zhou, N-Doped Carbon Nanorods as Ultrasensitive Electrochemical Sensors for the Determination of Dopamine, RSC Adv. 2 (2012) 8157.

[46] M. Hosseini, M.M. Momeni, M. Faraji, An innovative approach to electro-oxidation of dopamine on titanium dioxide nanotubes electrode modified by gold particles, J. Appl. Electrochem. 40 (2010) 1421-1427.

[47] G.L. Long, J.D. Winefordner, Limit of detection: a closer look at the IUPAC definition, Anal. Chem. 55 (1983) 712A-724A.

[48] L. Wu, L. Feng, J. Ren, X. Qu, Electrochemical detection of dopamine using porphyrin-functionalized graphene, Biosens. Bioelectron. 34 (2012) 57-62.

[49] G. Jiang, X. Gu, G. Jiang, T. Chen, W. Zhan, S. Tian, Application of a mercapto-terminated binuclear $\mathrm{Cu}(\mathrm{II})$ complex modified Au electrode to improve the sensitivity and selectivity for dopamine detection, Sens. Actuators B: Chem. 209 (2015) 122-130.

[50] E.A. Khudaish, F. Al-Nofli, J.A. Rather, M. Al-Hinaai, K. Laxman, H.H. Kyaw, S. Al-Harthy, Sensitive and selective dopamine sensor based on novel conjugated polymer decorated with gold nanoparticles, J. Electroanal. Chem. 761 (2016) 80-88.

[51] C.S. Santos, R.T. Ferreira, C.M.F. Calixto, J.L. Rufino, J.R. Garcia, S.T. Fujiwara, K. Wohnrath, C.A. Pessoa, The influence of organization of LbL films containing a silsesquioxane polymer on the electrochemical response of dopamine, J. Appl. Electrochem. 44 (2014) 1047-1058.

[52] P. Alessio, M.L. Rodríguez-Méndez, J.A. De Saja Saez, C.J.L. Constantino, Iron phthalocyanine in non-aqueous medium forming layer-by-layer films: growth mechanism, molecular architecture and applications, Phys. Chem. Chem. Phys. 12 (2010), 3972

[53] Y. Fan, H.-T. Lu, J.-H. Liu, C.-P. Yang, Q.-S. Jing, Y.-X. Zhang, X.-K. Yang, K.-J. Huang, Hydrothermal preparation and electrochemical sensing properties of TiO2-graphene nanocomposite, Colloids Surf. B: Biointerfaces 83 (2011) 78-82.

[54] S. Qi, B. Zhao, H. Tang, X. Jiang, Determination of ascorbic acid, dopamine, and uric acid by a novel electrochemical sensor based on pristine graphene, Electrochim. Acta 161 (2015) 395-402.

[55] F. Gao, X. Cai, X. Wang, C. Gao, S. Liu, F. Gao, Q. Wang, Highly sensitive and selective detection of dopamine in the presence of ascorbic acid at graphene oxide modified electrode, Sens. Actuators B: Chem. 186 (2013) 380-387.

[56] D.F. Davidson, Elevated urinary dopamine in adults and children, Ann. Clin. Biochem. 42 (2005) 200-207.

[57] D.P. Nikolelis, D.A. Drivelos, M.G. Simantiraki, S. Koinis, An optical spot test for the detection of dopamine in human urine using stabilized in air lipid films, Anal. Chem. 76 (2004) 2174-2180. 